\title{
An assessment of the human resource in eye care in the upper East region, Ghana
}

\begin{abstract}
The aim of the study was to measure the availability and distribution of human resources in eye care in the Upper East region. The study was a descriptive cross-sectional study. Data was collected from all government, private and Christian Health Association of Ghana (CHAG) eye care facilities in the region on the type and number of eye care professionals and their distribution. In total 38 eye care personnel were in the region: 1 ophthalmologist (2.63\%), 6 optometrist (15.79\%), 25 ophthalmic nurses $(65.79 \%)$ and 6 opticians $(15.79 \%)$. Two out of the 25 ophthalmic nurses coupled as cataract surgeons. The ophthalmologist to population ratio was 1: $1,046,545$, optometrist to population ratio was $1: 174,424$, ophthalmic nurse to population ratio was $1: 41,861$ and optician to population ratio was 1 : 174,424 . Of the 38 eye care personnel in the region, 15 (39.47\%) worked in the government sector, $3(7.90 \%)$ worked in the private sector and $20(52.63 \%)$ worked with the Christian Health Association of Ghana (CHAG). Majority $(97.37 \%)$ of the eye care personnel were located in the urban part of the region, with just $1(2.63 \%)$ eye care personnel in a rural area. The human resource for eye care presently available in the Upper East region is inadequate. Eye care professionals are poorly distributed, with severe shortage of personnel in the rural and isolated part of the region. Most of the eye care human resources in the region are located in urban centers and CHAG facilities.
\end{abstract}

Keywords: distribution, ophthalmologist, optometrist, ophthalmic nurse, optician
Volume 7 Issue 6 - 2017

Prince Kwaku Akowuah,' Merepa SS,' Abazele AS,' Gyamfi JA, ${ }^{2}$ Gyekye-Darko NA,' Djeagbo PT,' Adjei-Anang J'

'Department of Optometry and Visual Science, College of Science Kwame Nkrumah University of Science and Technology, Ghana

${ }^{2}$ Department of Optometry and Visual Science, University of Cape Coast, Ghana

Correspondence: Prince Kwaku Akowuah, Department of Optometry and Visual Science, College of Science Kwame Nkrumah University of Science and Technology, Kumasi, Ghana, Email prince.k.akowuah@gmail.com

Received: October 29, 2017 | Published: December 04, 2017

\section{Introduction}

Globally, approximately 285 million people are visually impaired: 39 million blind and 246 million having low vision, ${ }^{1}$ about $90 \%$ of which is found in low income settings. ${ }^{2}$ Most (80\%) visual impairments can be prevented or cured with cataract and uncorrected refractive errors accounting for the majority of preventable visual impairments. ${ }^{3}$ Unavailable or limited eye care services and restricted access to eye care services (both geographically and financially) are two major reasons for the high rate of preventable visual impairment. Throughout the world, especially in developing countries, eye care is a neglected aspect of health, with a significant number of health care centers without eye care facilities or personnel. In Ghana, eye care is largely institution based and run by ophthalmologist, optometrist and ophthalmic nurses in big cities and town with general practitioners and pharmacist providing some primary care and referring when necessary. This leaves most of the rural communities in Ghana lacking needed eye care services. However, if the goals of the "VISION 2020" and "Universal Eye Health" initiatives are to be achieved, the lack of adequately trained eye care personnel in a large portion of the country is one major thing that needs to be improved. The aim of the study was to measure the availability and distribution of the human resources in eye care in the Upper East region, Ghana.

\section{Materials and methods}

The study was carried out in the Upper East Region of Ghana The Upper East Region is located in the north-eastern corner of the country, between longitude 00 and 10 West and latitudes 10030 "N and $110 \mathrm{~N}$. The region is bordered to the north by Burkina Faso, the east by the Republic of Togo, the west by Sissala District in Upper West and the south by West Mamprusi District in Northern Region. According to the Population and Housing Census in 2010, the Upper East region is $79 \%$ rural and $21 \%$ urban. The region comprises 2 municipalities and 11 districts: Bawku Municipal District, Bawku West District, Binduri District, Bolgatanga Municipal District, Bongo District, Builsa District, Builsa South District, Garu - Tempane District, Kassena Nankana East District, Kassena Nanakana West District, Nabdam District, Pusiga District and Talensi District. ${ }^{4}$ According to the Population and Housing Census in 2010, the population of the region is $1,046,545$ and can be highly regarded as rural (79\%) leaving only $21 \%$ of the region's population urban.

The study was a descriptive cross-sectional study. A structured question was used to collect data from all government, private and Christian Health Association of Ghana (CHAG) eye care facilities in the region on the type and number of eye care professionals and their distribution. Only eye care professionals who had undergone the required number of training in their respective fields and have been duly licensed to practice in Ghana were considered for the study. All the private facilities included in the study were licensed. Permission was obtained from the authorities of the eye care facilities within the region. The period of data collection was from February 1, 2017 to March 31, 2017. The data was analyzed using the Statistical Package for Social Scientists (SPSS) software version 20.0 and Microsoft Excel (2010). 


\section{Results and discussion}

\section{Eye care facilities}

A total of 10 eye care facilities were in the Upper East region: 5 government facilities (located in Sandema, Navrongo, Bolgatanga, Bongo and Tongo), 2 private facilities (located in Missiga and Bawku) and 3 CHAG facilities (located in Bawku, Yorogo and Garu, Garu Tempane). Seven of these facilities had been operating for more than 3 years and other 3 had been operating for $\leq 3$ years. Two of the 3 CHAG facilities and all the private and government eye care facilities were located in urban areas. Only one eye care facility (a CHAG facility) was operating in a rural area (Yorogo). According to the 2010 population census in Ghana, the population of the Upper East Region was $1,046,545 .{ }^{5}$ With just 10 eye care facilities in the region, each facility would be serving approximately 104,654 individuals in the region. The distribution of these eye care facilities within the region are uneven (depicted in plate 1.0$)$. Nine $(90.00 \%)$ of these facilities are located in the regional capital and district capitals within the region, which are urban areas. With majority (79\%) of the region being rural, the distribution of the facilities does not favor the rural populace, who form a greater percentage of the population. This has the potential of being a barrier (geographical and financial) to eye care seeking as visiting these eye care facilities would involve long travels and extra cost for most of the rural populace. A study by Merepa et al. ${ }^{6}$ in the Upper East region identified cost of transportation and the distance to eye care facility as barriers to utilization of eye care services. Several other studies have established distance to eye care facility and the cost of transport to facility as barriers to utilization of eye care services. ${ }^{7-9}$

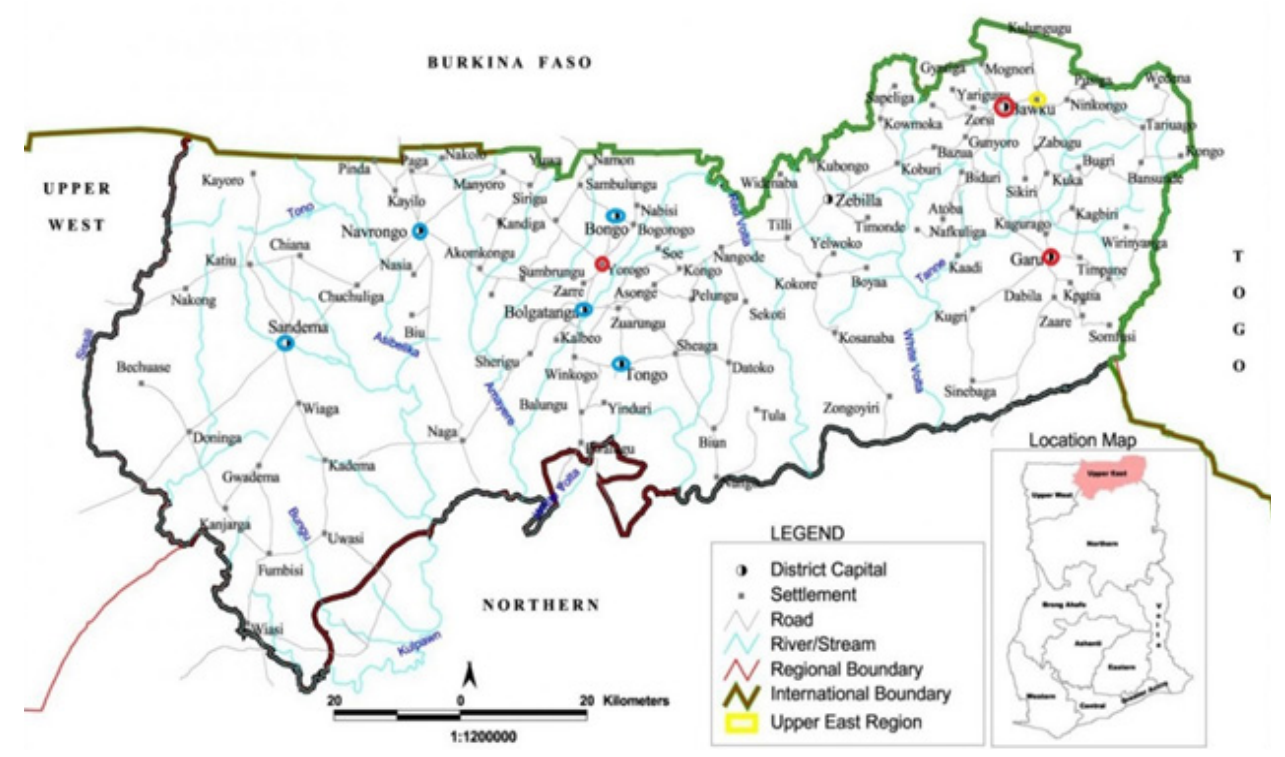

Figure I Map showing location and distribution of the facilities within the region.

\section{Eye care personnel}

Thirty-eight (38) eye care personnel's worked in the 10 eye care facilities within the region: 1 ophthalmologist, 6 optometrist, 25 ophthalmic nurses and 6 opticians. Two of the ophthalmic nurses coupled as cataract surgeons (Table 1). Thirty-seven (97.37\%) of the eye care personnel in the Upper East region worked in the urban part of the region, while only $1(2.63 \%)$ worked in the rural part of the region. The eye care workforce in the Upper East Region of Ghana appears to be inadequate by World Health Organization (WHO) standards. With an ophthalmologist to population and optometrist to population ratios of $1: 1,046,545$ and $1: 1,147,424$ respectively, the eye care force of the Upper East region falls short of the WHO standards of 1:250,000 and $1: 100,000$ by 2020 . The current ophthalmologist to population ratio in the region lags the WHO standards by over $300 \%$ while the optometrist to population ratio lags the WHO standards by over $80 \%$. The study been conducted in 2017, just 3 years from the 2020 target year of the VISION 2020 initiative, shows that the region has a long way to go in meeting the WHO standards by 2020. The ophthalmic nurse to population ratio however, meets the WHO standard. With a ratio of $1: 44,876$, the ophthalmic nurse to population ratio beats the WHO standard of 1:100,000. Aside the inadequate number of eye care professionals, the distribution of the limited human resource is not one to write home about. Thirty-seven $(97.37 \%)$ of the 38 eye care professionals in the region work in the urban part of the region, leaving the $79 \%$ of the region in dire need of eye care professionals (Table 2).

Table I Eye Care Personnel in the Upper East Region and the Type of Facility They are Located in

\begin{tabular}{lllll}
\hline Personnel & Government [n (\%)] & Private [n (\%)] & CHAG [n (\%)] & Total [n (\%)] \\
\hline Ophthalmologist(s) & $0(0)$ & 0 & $\mathrm{I}(2.63)$ & $\mathrm{I}(2.63)$ \\
Optometrist(s) & $3(7.89)$ & 0 & $3(7.90)$ & $6(15.79)$ \\
Ophthalmic nurse(s) & $8(21.05)$ & $3(7.90)$ & $14(36.84)$ & $25(65.79)$ \\
Optician(s) & $4(10.53)$ & 0 & $2(5.26)$ & $6(15.79)$ \\
Total [n (\%)] & $15(39.47)$ & $3(7.90)$ & $20(52.63)$ & $38(100)$ \\
\hline
\end{tabular}


Table 2 Eye Care Personnel to Population Ratio of Upper East Region Compared With WHO Recommended Ratio

\begin{tabular}{llll}
\hline Personnel & Number & ratio & WHO recommendation \\
\hline Ophthalmologist & $\mathrm{I}$ & $\mathrm{I}: 1,046,545$ & $\mathrm{I}: 250,000$ \\
Optometrists & 6 & $\mathrm{I}: 174,424$ & $\mathrm{I}: 100,000$ \\
Ophthalmic nurses & 25 & $\mathrm{I}: 4 \mathrm{I}, 86 \mathrm{I}$ & $\mathrm{I}: 100,000$ \\
Opticians & 6 & $\mathrm{I}: 174,424$ & Not available \\
\hline
\end{tabular}

This trend of uneven distribution of health care personnel (especially eye care workforce) has been reported in other studies. ${ }^{10-15}$ Studies in Ghana, ${ }^{16}$ Nigeria $^{10,17}$ and Afghanistan ${ }^{18}$ reported eye care personnel's were woefully inadequate and poorly distributed. A study by Husainzada in Afghanistan, reported similar findings of about $87 \%$ of eye care professionals in urban Afghanistan and just $13 \%$ of them in rural Afghanistan. Furthermore, the ophthalmologist to population ratio of the 1:200,000 reported in the Afghanistan study lags the WHO standards by $100 \% .^{18}$ With this uneven distribution, rural populace would have to travel long distances before they can attain the services of an eye care personnel. Also, with just one eye care facility in the rural areas, the patient load on that eye care facility would be extremely high, which would result in longer waiting time at the facility. Distance to eye care facility, cost of transport and longer waiting time at health care facilities are established barrier to utilization of eye care services in the region. ${ }^{6}$ A study in Nigeria to determine the barriers to utilization of eye care services reported similar finding of waiting time, distance to eye care facility and cost of transportation in addition to no perceived need for eye care services, cost, social engagement and need for escort. ${ }^{7}$

Considering the Upper East region in relation to the whole country, things are not different. The Upper East region appears to be woefully underserved in terms of eye care force in relative to other parts of the country. Ghana has about 74 ophthalmologists working in government, CHAG or private facilities. With just one ophthalmologist in the region, the Upper East region benefits from the services of less than $2 \%$ of the ophthalmologist workforce in Ghana. Due to the inadequate number of ophthalmologists within the region, two ophthalmic nurses were trained by the CHAG facilities to couple as cataract surgeons to supplement surgical procedures in other to attain the required Cataract Surgical Rate ${ }^{19}$ which is an indicator for the attainment of the Vision 2020 initiative. With over $50 \%$ of blindness due to cataract occurring in the poor or remote areas of the world,$^{20}$ it would be more logical to have the higher number of ophthalmologist and cataract surgeons in those parts of the world. However, most of these eye care personnel are practicing in the urban areas of the world where their services are less needed compared to the need of the poor rural areas.

\section{Conclusion}

The human resource for eye care presently available in the Upper East region is inadequate. Eye care professionals are poorly distributed, with severe shortage of personnel in the rural and isolated part of the region. Most of the eye care human resources in the region are located in urban centers and CHAG facilities.

\section{Acknowledgments}

We say a big thank you to the authorities of the various eye care facilities in the Upper East region for allowing us to use their facilities as a point for our study and also to the various staff members that assisted us in any form during the study.

\section{Conflicts of interest}

The authors declare that there is no conflict of interest concerning this publication.

\section{Funding}

None.

\section{References}

1. Thylefors B, Negrel AD, Pararajasegaram R, et al. Global data on blindness. Bull World Health Organ. 1995;73(1):115-121.

2. WHO. Visual impairment and blindness. World Heal Organ. 2013;61253.

3. Resnikoff S, Foster A. The impact of Vision 2020 on global blindness Eye. 2005;19(10):1133-1135

4. Ghana Statistical Service. 2010 Population and Housing Census, District Analytical Report. Ghana Stat Serv. 2014; p. 1-109.

5. GSS. 2010 Population and Housing Census: Regional Analytical Report 3. 2013.

6. Merepa SS, Akowuah PK, Abazele AS, et al. Barriers to Utilization of Eye Care Services in the Upper. Adv Ophthalmol Vis Syst. 2017;140:107-110.

7. Ebeigbe JA, Ovenseri-Ogbomo GO. Barriers to utilization of eye care services in rural communities in Edo State, Nigeria. Borno Med J. 2014;11(2):98-104.

8. Kimani K. Barriers to utilization of eye care services in Kibera and Dagoreti, Kenya. Joecsa. 2013;14:55-61.

9. Kovai V, Krishnaiah S, Shamanna BR, et al. Barriers to accessing eye care services among visually impaired populations in rural Andhra Pradesh, South India. Indian J Ophthalmol. 2007;55(5):365-371.

10. Dussault G, Franceschini MC. Not enough there, too many here: understanding geographical imbalances in the distribution of the health workforce. Hum Resour Health. 2006;4:12.

11. Anyangwe SC, Mtonga C. Inequities in the global health workforce: The greatest impediment to health in Sub-Saharan Africa. Int $J$ Environ Res Public Health. 2007;4(2):93-100.

12. Zurn P, Dal Poz MR, Stilwell B, et al. Imbalances in the health workforce Hum Resour Health. 2004;2(1):13.

13. Leon BK, Riise Kolstad J. Wrong schools or wrong students? The potential role of medical education in regional imbalances of the health workforce in the United Republic of Tanzania. Hum Resour Health. 2010;8:3.

14. Marchal B, Kegels G. Health workforce imbalances in times of globalization: Brain drain or professional mobility. Int $J$ Health Plann Manage. 2003;18(Suppl 1):S89-S101.

15. Munga MA, Mæstad O. Measuring inequalities in the distribution of health workers: the case of Tanzania. Hum Resour Health. 2009;7:4.

16. Ilechie AA, Otchere H, Darko-Takyi C, et al. Access to and utilization of eye care services in Ghana. Int $J$ Heal Res. 2013;6:7-15.

17. People deliver eye care: Managing human resources. Community Eye Health. 2005;18(56):117-119.

18. Husainzada R. Situation analysis of human resources in eye care in Afghanistan. Community Eye Heal J. 2007;20(61):12.

19. Lewallen S, Roberts H, Hall A, et al. Increasing cataract surgery to meet Vision 2020 targets; experience from two rural programmes in east Africa. Br J Ophthalmol. 2005;89(10):1237-1240.

20. Rao GN, Khanna R, Payal A. The global burden of cataract. Curr Opin Ophthalmol. 2011;22(1):4-9. 